\title{
HISPANIA: HUELLAS DE LA CONQUISTA ROMANA. APROXIMACIÓN AL ESTUDIO DE LOS FOSOS DE LOS ASENTAMIENTOS MILITARES PENINSULARES
}

\author{
Noelia SABUGO SoUSA \\ Universidad de León
}

\begin{abstract}
RESUMEN: La conquista de la Península Ibérica por parte de las armas romanas fue un proceso largo y costoso. Los asentamientos militares jugarán un papel destacado en el transcurrir de este proceso, tanto a nivel de pernocta y refugio de las legiones como de elementos de asedio y cerco de un gran número de núcleos indígenas. Hispania es un terreno privilegiado y podríamos decir que casi único en cuanto a la riqueza de vestigios de este tipo documentados en nuestro suelo.
\end{abstract}

PALABRAS CLAVE: Arqueología militar romana; ejército romano; topografía; guerra; campamentos; foso.

ABSTRACT: The conquer of the Península Iberica by the Roman arms was a long and difficult process. The martial camps had an important role in the development of this process either as a place of refuge of the Legions or as a besiegement element of a great number of indigenous places. Hispania is a privileged land and we can even say that it is almost a unique case as far as the richness of vestiges of this kind documented in our ground is concerned.

KEYWORDS: Roman military archaeology; Roman Army; topography; war; camps; ditch.

Roma, la elegida de los dioses, la ciudad descendiente de la mítica Ilión, unos ciudadanos llamados a la grandeza. Podríamos marcar como hito fundamental del comienzo de la expansión romana los enfrentamientos con Cartago. Será a partir de la segunda guerra púnica cuando el descollante poder de las águilas haga su aparición fuera de las fronteras itálicas: Hispania, Galia, Germania, Britannia, etc. ningún terreno conocido, ningún suelo, ningún reino parecía estar demasiado lejano o resultar inaccesible para un ejército tan disciplinado y entrenado como el constituido por las legiones romanas. No podemos llevarnos a engaño, no es sólo la fuerza de los hombres la que conlleva el dominio de un sinfín de pueblos y la expansión de la urbe hasta la conformación de un gran imperio, sino todo un entramado logístico perfectamente organizado y orquestado desde la propia Roma: grandes generales, construcciones resistentes, adiestramiento, organización, 
disciplina, adaptación al medio, capacidad de superación, orgullo y honor, etc. Son todas ellas cualidades que brillan con luz propia dentro del discurrir de un pueblo cuyo nombre, incluso hoy en día, evoca la grandeza.

El lento transcurrir de los siglos no ha borrado ni un ápice del esplendor y de la magia que nos viene a la mente al pronunciar la palabra "romanos": un "grupo de pastores" que funda su patria en torno a siete colinas llegará a dominar, de punta a punta, el mundo conocido. Parecía un milagro, un prodigio de los dioses, algo extraño a los ojos del pensador contemporáneo, un solo pueblo fiscalizando tan vasto y extenso imperio; ¿cómo era posible?, ¿cuáles eran sus recursos?, ¿cuál su sistema de control?, ¿de qué medios se servían para lograr someter a los pueblos?, ¿cómo lograron tener bajo su égida a tan diversos, dispersos y heterogéneos habitantes?. La respuesta, aunque compleja y con gran diversidad de matices, podría resumirse en torno a dos actuaciones principales. En primer lugar, un sometimiento por medio de las armas, el uso de la violencia como vía de control y ocupación, para concluir con una lenta, progresiva y constante incorporación a las formas de vida traídas desde las orillas del Tíber. Se trataría de lograr que estos nuevos componentes del imperio acabaran adoptando y viendo como propias unas costumbres, en principio, ajenas.

El presente texto tiene por objetivo centrarse en la primera de las dos actuaciones citadas anteriormente (análisis cuyo campo de acción hemos enmarcado en los límites de la península ibérica): la coerción por medio de las armas. Concretamente trataremos de arrojar un poco de luz en torno a un elemento tan olvidado como han sido los fosos que circundaban los castra romanos. Parece ser que, hasta hace relativamente poco, eran solo las batallas espectaculares, los hechos heroicos, los poderosos ejércitos, etc. los que habían logrado dar al nombre de Roma el lustre y grandeza que poseía. Lentamente van ocupando su lugar otros factores tanto o más importantes que los que acabamos de citar: el medio físico, los asentamientos, los suministros, etc.

La larga duración de la conquista romana de Hispania, que se prolonga durante dos siglos (218-19 a. C.) y la trascendencia de algunos episodios históricos como las guerras celtibéricas y sertorianas, han atraído tradicionalmente la atención de los investigadores hacia los campamentos erigidos en nuestro suelo. España conserva una de las mejores colecciones de campamentos romanos, aunque, tradicionalmente, su estudio y valoración ha mostrado un serio retraso con respecto a sus homólogos de Britannia y Germania, debido en la mayoría de los casos a la clara indolencia mostrada en torno a la valoración de la estrategia militar romana aplicada a la Península (Morillo, 2005). 
La táctica y la estrategia conformaron dos puntos fundamentales en torno a los que se movería el desarrollo de las campañas legionarias; la primera entendida como el conjunto de reglas a las que se debían sujetar las operaciones militares para conseguir el fin propuesto; mientras que la segunda, se referiría al uso de todos los conocimientos militares adquiridos en torno a una cuestión, para buscar la forma más adecuada de conseguir los objetivos marcados, recurriendo para ello al empleo de unos medios. En este caso, el objetivo era el control territorial y reconocimiento por parte de otros pueblos del poderío romano; el medio utilizado para lograrlo era la guerra y el conocimiento técnico que de la misma poseían los romanos les lleva a imponer su dominio sobre el orbe conocido.

\section{ERIGIENDO LOS CIMIENTOS}

Corría el año 218 a. C. cuando Escipión desembarcaba con sus tropas en un terreno nunca antes hollado por los pies romanos. El enfrentamiento con los púnicos minaba sus recursos y su poderío; era necesario cortarles su principal fuente de abastecimientos y dejarles aislados y sin puntos de apoyo. De esta manera, Hispania entra a formar parte de la historia de Roma. Lo que se presentaba como una actuación de liberación del control cartaginés se convertirá en una ocupación permanente y en una explotación sistemática y organizada de las nuevas tierras controladas por la republica.

Apoyándose en las legiones y valiéndose de su superioridad técnica, militar, estratégica, diplomática, etc. Roma se hace presente y patente. La riqueza que se vislumbraba en nuestras tierras no pasó desapercibida y el apetito de la loba se despertó.

Algunos episodios de la conquista fueron vistos desde Roma como una sangría de hombres. Muchos ciudadanos romanos, aliados y auxiliares perdieron la vida en pos de la consecución de la ampliación del Estado. Nuevas legiones llegaban a la Península. Pocas salían indemnes de ella. Los hombres que las conformaban servían al ideal de la grandeza del estado (sobre todo en época republicana). Duros entrenamientos les hacían adquirir la denominación de milites, pero no fueron tan necios como para sólo confiarse a la fuerza de su formación táctica en las batallas. La vida del militar no transcurre en enfrentamientos continuos con el enemigo, también es necesario desplazarse sobre el terreno, controlar el territorio, preparar la guerra, conocer al enemigo, etc. Para todo ello era necesario dotarse de asentamientos en los cuales ponerse a resguardo de posibles ataques. Es aquí donde comenzaremos a tratar sobre los campamentos.

La mayor parte de la vida de los soldados transcurría dentro de los recintos castrenses, los cuales se convertían en su nuevo hogar. Desgraciadamente, las 
fuentes clásicas que han llegado hasta nosotros no nos han transmitido la denominación con que eran conocidas entre los reclutas las instalaciones que los albergaban. Conocemos la voz latina castra, cuya traducción nos ha servido para agrupar estos asentamientos bajo la designación de campamentos, pero hemos de tener en cuenta que, en relación a su capacidad, función, duración, tipo de defensas y otras variantes similares, su descripción podría ajustarse a términos como fortaleza, fuerte, fortificación, torre, castillo, guarnición, etc. ${ }^{1}$

Nos parece acertado el clarificar el término campamento, pues una de las estructuras defensivas que lo conforman es el eje vertebrador del presente trabajo. Un castra sería aquel establecimiento que sobre el terreno estaría dotado de unas defensas poco potentes, formadas por foso, terraplén y empalizada (sistema de agger), y en el que la necesidad de adecuarse a un trazado predeterminado quedaba relegada a un lugar secundario en pos de conseguir adaptarse a las condiciones naturales que ofrecía el terreno y que proporcionarían una serie de importantes ventajas frente al enemigo. Es importante señalar la diferencia existente entre campamento temporal (castra aestiva) y campamento permanente (castra hiberna o stativa). Ambos términos podrían actuar como equivalentes, pero aquí el tiempo de duración será usado como referencia para establecer su distinción; los temporales eran aquellos que estaban destinados a proteger la pernocta del ejército durante breves períodos de tiempo (una o dos noches), siendo destruidos por sus propios constructores antes de reemprender la marcha; fueron erigidos en madera, levantados con rapidez y destruidos a igual velocidad, por lo que apenas nos han legado restos. Los campamentos permanentes serían aquellos destinados a un asentamiento sobre el terreno más prolongado en el tiempo; generalmente incluimos en este grupo los cuarteles de invierno, dentro de los cuales la legión viviría los períodos no aptos para el desarrollo de enfrentamientos bélicos en campo abierto. En contraste con los anteriores su extensión sería mayor y más recias sus defensas. El uso del tiempo como marca delimitadora nos da unos resultados muy tenues e imprecisos, ya que no podemos señalar con precisión el momento en que un recinto deja de ser temporal para convertirse en permanente. Además hemos de tener en cuenta que las diferencias entre un modelo y otro residían más en su tamaño y funcionalidad que en el material utilizado para su construcción y el tiempo que permanecían asentadas sobre un mismo punto geográfico.

\footnotetext{
${ }^{1}$ La limitación del espacio nos impide tratar en mayor profundidad este tema, pues su explicación excede los límites del presente trabajo, aún así es de vital importancia el señalar la existencia de todas estas diferencias en orden a evitar errores de inclusión y catalogación de los diferentes recintos estudiados.
} 
La disciplina seguida por los soldados romanos es digna de admiración, una legión era mucho más que un grupo de hombres que luchaban juntos. Al final de cada jornada de marcha cuando se detenían para hacer noche, levantaban un campamento. Su tarea no era sólo la militar, sino que actuaban como ingenieros, arquitectos, elementos de romanización, etc. ${ }^{2}$ Los recintos castrenses estaban construidos siempre igual, siguiendo unos patrones que ya conocían y que llevaban a cada uno a realizar su trabajo y colaborar hombro con hombro. En este ambiente de corporativismo cobra sentido uno de sus mejores ejemplos: la capacidad de estos hombres de erigir cada noche unos asentamientos tan perfectamente diseñados y rodeados de un sistema de defensas tan elaborado.

En cuanto a la forma que adoptaban estos recintos hemos de decir que Polibio e Higinio, las dos principales fuentes clásicas de nuestro tema de estudio, nos legan una descripción que los agrupaba en torno a un perfil cuadrado o rectangular, respectivamente ${ }^{3}$. No debemos obviar que las descripciones de estos autores se encuentran separadas por un intervalo de quinientos años de historia, por lo que la evolución de los recintos castrenses se ha ajustado a los cambios experimentados a lo largo de estos años en la propia composición de los ejércitos ${ }^{4}$. No podemos señalar con exactitud el momento en que se produce el cambio de la utilización de uno u otro modelo, se cree que éste tendría lugar a lo largo del mandato de César, pero en este punto, seguimos moviéndonos en el terreno de las hipótesis.

Vegecio, a su vez, nos señala que, en dependencia con la figura que los mismos adoptaban, habría de tenerse en cuenta la situación, la naturaleza del sitio y lo que

${ }^{2}$ Un legionario romano en campaña debía cargar con más cosas aparte de sus armas, armadura, comida y posesiones personales. Debía llevar toda una amplia gama de herramientas destinadas a acometer los trabajos de erección de los reales. Entre las más importantes podemos destacar las siguientes: palas, picos, dolabras (instrumento que combinaba una hoja cortante con un pico), cestos, espuertas, azada y azadones usados para abrir los fosos y hachas, destrales (hacha pequeña), honcejos (sierra para madera de hoja ancha y curva), sierras, etc. El soldado profesional romano era tanto un infante como un ingeniero de combate.

${ }^{3}$ Para Polibio las dimensiones canónicas del castra rondarían en torno a 2.017 pies romanos, es decir, 596,42 metros, lo que nos deja con una superficie de 35,57 ha. (para dar cabida a un ejército consular). Higinio transmite unas medidas que oscilarían entre los 2.320 pies para los lados largos y los 1.620 para los más estrechos (680 x 480 metros), diseñados para el acomodo de tres legiones acompañadas de sus cuerpos auxiliares. No podemos obviar el hecho de que los cálculos sobre el papel son siempre perfectos, mientras que en el terreno éstos cambian en gran medida. Las fuentes escritas, en muy raras ocasiones, nos van a transmitir la extensión ocupada por los ejércitos para la pernocta, serán los trabajos arqueológicos los que nos permita jugar con las cifras.

4 La modificación más trascendental fue la inclusión de las tropas auxiliares dentro del campamento tras las reformas de Mario. 
la necesidad permitiese, dando lugar a una gran variedad de trazados: castra lunata (en forma de creciente lunar), castra necessaria (adecuándose a las necesidades impuestas por el terreno), castra semirotunda (sólo se erigen defensas por uno de sus lados), castra tumultuaria (los campamentos de campaña que se fortificaban como se pudiese), triangular, ovalado, además, de los perfiles ya señalados por Polibio e Higinio, etc. Existían tantos perfiles como cualidades del terreno a las que adaptarse.

El agger conformaba el núcleo defensivo de los campamentos de marcha. Uno de sus elementos más importantes era el foso, estructura en torno a la cual se distribuía y organizaba el resto del entramado. Eran los ingenieros (metatores o agrimensores), en época republicana, y el "prefecto de los campamentos", 5 a lo largo del Imperio, los encargados de señalar el lugar en el que se iban a asentar los reales, ${ }^{6}$ disponer sus medidas ${ }^{7}$ y establecer la distribución de cada uno de sus elementos, siendo los legionarios los encargados de llevar a cabo la construcción de los mismos (Polibio, Hist., VI, 41-42).

Vegecio (III, 8) pone de manifiesto el hecho de que a cada una de las centurias que componían la legión se le asignaba un trecho de la zanja a cavar o bien se la implicaba en el trabajo de construcción del terraplén:

"Los campamentos, donde se ha de permanecer en invierno o en verano cuando el enemigo está cerca, se han de fortificar con mayor cuidado y

${ }^{5}$ Esta figura (praefectus castrorum) debe ser tratada con cuidado, ya que no existía en época republicana, sino que fue una de las reformas introducidas por Augusto en la organización militar. Tenía bajo su cuidado el control de "los carros, acémilas y herramientas con que se cortan las maderas para hacer las estacadas, con que se abren los fosos, los pozos y los acueductos" (Vegecio, Epitome, II, 10). Eran hombres escogidos entre aquellos que habían dado mayores pruebas de conocer y dominar el arte de la guerra.

${ }^{6}$ A la hora de elegir el lugar de asentamiento había que tener en cuenta una gran diversidad de factores, tales como tratarse de una zona elevada (Vitrubio, De Arch., I, IV; Frontino, Strat., I, V, 11 ó II, II, 2, 3, 4 y 6); tener en cuenta los vientos; buenas vías de comunicación; acceso al agua y otras provisiones en abundancia; asentarse cerca de montes y lagunas para lograr protección natural por uno de los flancos del recinto (Frontino, Strat., II, III, 9; Floro, I, II, 8, 15); lugares con buena visibilidad; salubridad (Vegecio, III, 2); rápida capacidad de maniobra (Higinio, 56); etc.

7 Ajustándose en todo momento al número de tropas que debían albergar y teniendo siempre presente que si se pecaba de reducir la superficie, los hombres estarían impedidos por la falta de espacio, no podrían realizar bien sus trabajos, ni disponerse con corrección sobre el terreno y se estorbarían unos a otros. Por el contrario, si la extensión era demasiado amplia, el terreno a defender rebasaría la capacidad del ejército y dejaría espacios expeditos a los ataques enemigos, se entorpecería la organización estructural y los soldados se encontrarían demasiado esparcidos dentro del campamento (Higinio, De mun. castr. 31-47). 
trabajo. Se señala y se mide por pasos el terreno que corresponde fortificar a cada centuria, y poniendo los soldados alrededor de las banderas sus escudos y mochilas sin quitarse la espada abren un foso".

Cada una de las actividades acometidas por los soldados que componían la centuria, no era dejada al azar, ya que, a pesar de la gran experiencia de algunos de los mismos y del constante entrenamiento que todos recibían, el trabajo que acometían era constantemente medido y supervisado por los centuriones. Estos últimos eran los encargados de cerciorarse de que el proceso de construcción de las defensas se llevaba a cabo con precisión y rigor.

Jugaba un papel muy destacado el conocer el terreno, aunque fuese superficialmente, para poder escoger el lugar que mayores ventajas ofreciese. Para ello era necesario mandar por delante de la marcha de la legión un cuerpo expedicionario que reconociera la superficie y que al llegar el grueso de la marcha al final del trayecto se tuviera ya escogido y suficientemente delimitado el espacio para construir; de esta forma no se perdía tiempo inútilmente, ni se tenía a los soldados inactivos. Además el tiempo escaseaba y los trabajos debían ser llevados a cabo sin prisa, pero sin excesiva pausa, para dar vida al conjunto de estructuras que les darían cobijo durante el transcurso de una o varias noches. Nunca las tropas romanas dan batalla al enemigo antes de asentar su campamento, a no ser que fueran objeto de una emboscada o que se produjera un ataque sobre la columna en marcha.

Cuando el ejército se veía "forzado" a establecerse en lugares inapropiados o en los cuales no se reunían las características prefijadas de antemano en los manuales se denominaba a la posición ocupada por los reales con el sobrenombre de "madrastra". Se recomendaba encarecidamente evitar este tipo de asentamientos a toda costa (próximos a montañas que puedan conceder ventajas al enemigo, tanto tácticas como visuales; cercanía de bosques; barrancos o pequeños valles; obviar la contigüidad de ríos o torrentes de agua cuya crecida pueda inundar o suponer un peligro grave; etc.).

La erección de los campamentos era la respuesta a las duras marchas llevadas a cabo cada día por las legiones ${ }^{8}$. Estos recintos tenían que cumplir tres requisitos indispensables: que sus dimensiones respondiesen a la hechura exacta necesaria

\footnotetext{
${ }^{8}$ La distancia media que solían cubrir las legiones a lo largo de un día de marcha era de unas 20 millas romanas $(30 \mathrm{~km})$ en cinco horas, pero en caso de necesidad esta distancia podía ser ampliada en función de la rapidez con que su presencia fuera requerida en una zona determinada o según el terreno por el que transitara, llegando a ser capaces de recorrer 24 millas (36 km) en esas mismas cinco horas.
} 
para albergar a las legiones, una correcta disposición sobre el terreno y estar dotados de unas defensas que fuesen adecuadas a su finalidad. El momento justo en que los hombres comenzaban el trabajo para la erección de la nueva estructura defensiva era el preferido por las tropas enemigas para caer sobre los soldados, cuando éstos se encontraban todavía con la carga a cuestas. La marcha había concluido, pero todavía los bagajes no habían sido organizados, ni se había comenzado la erección del recinto, era el momento perfecto. Embarazados con la carga ${ }^{9}$ sin formación y desorientados eran presa fácil, de lo que se desprende la importancia que adoptará la defensa de los mismos cuando se encuentren enfrascados en los trabajos de construcción. Hemos de observar que si no existía un gran peligro los soldados trabajaban desarmados, constituyendo un blanco muy apetecible; además cuando sus faenas eran llevadas a cabo sobre las armas sólo portaban con ellos la espada colgada del cinto (Vegecio, III, 8), lo cual tampoco suponía un seguro de salvación, ya que no contaban con escudos para protegerse.

El espacio que debía ocupar el campamento quedaba delimitado por la conjunción del foso y el terraplén, siendo designado este terreno como sacro o sagrado. El circuito definido por la conjunción de ambos elementos en torno a los reales creaba un aura de religiosidad, que retrotraía al sistema seguido por los etruscos a la hora de fundar una ciudad. No debemos olvidar que muchos campamentos son el origen y dan lugar al desarrollo de un gran número de ciudades (de las que hoy en día muchas siguen siendo activos y destacados núcleos poblacionales). Uno de los sentidos que podemos dar a la realización de este tipo de trazado se puede encontrar en la propia historia de la fundación de Roma (Livio, Ab urbe, I, 7, 1-3 y Ovidio, Fastos, 4.835-48).

A partir de este punto centraremos nuestra atención en los fosos que rodeaban el campamento. Esta estructura jugaba un importante papel en su entramado defensivo. A la hora de erigir el campamento la excavación de las trincheras era el primer trabajo que debía ser acometido por los soldados, claro está, después de que los agrimensores hubieran señalado el terreno que iba a ocupar el asentamiento y el lugar por donde debía discurrir el trazado de la misma. Estos fosos solían responder a las medidas de 9 pies romanos de anchura y 5 de profundidad ${ }^{10}$. Acometer esta

9 Los soldados romanos cuando marchaban con las armas solas se decían expediti o in expeditionem (pues, según escribe Cicerón, las armas no se tenían entre ellos por carga); cuando iban cargados de las mochilas, utensilios y estacas para el vallado, impediti o sub sarcinis.

${ }^{10}$ Unos $2,70 \times 1,50$ metros, hemos de señalar que estas medidas sólo tienen un carácter orientativo, pues la amplitud de los fosos variaba en función de las necesidades del asentamiento donde eran excavados. 
tarea en primer lugar era de singular importancia, ya que proporcionaba el material necesario para la realización del terraplén defensivo; hecho relevante si en el terreno donde se encontraba asentada la legión existía escasez de elementos convenientes para la realización del mismo. Siguiendo este método los romanos se ahorraban un doble trabajo, ya que la tierra que era extraída de los atrincheramientos era usada para la erección de la rampa (por lo que era apilada hacia la parte interior), con lo que solventaban, a un mismo tiempo, el problema de deshacerse del material extraído de la trinchera y obviaban la búsqueda del mismo para la construcción del terraplén.

En función de la ubicación, de la duración del asentamiento, de la proximidad enemiga, de la naturaleza del lugar, etc., el número de fosos con los que un perímetro podía estar rodeado variaba. No existían patrones fijos de comportamiento en torno a la excavación de los mismos. Podía dotarse a un recinto de un amplio número de ellos o de ninguno, estar presentes en alguno de sus lados, sólo en sus ángulos, o en aquellas zonas donde la visibilidad fuese menor, así como estar totalmente ausentes si la propia creación había convertido aquel terreno en un lugar inexpugnable. Hemos de decir que casi todos los campamentos de marcha de los que tenemos constancia contaron al menos con un foso, ya que el terreno que pisaba la legión al final de la jornada no siempre ofrecía a los soldados parajes aptos. Era la disciplina del trabajo la que suplía las desventajas físicas y geográficas (César, De bell. Gall., VII, LXXII ó VIII, 9; De bell. Afric., XX, LI; Livio, Ab urbe, XL, 33; etc.).

El uso del foso y la trinchera no pueden ni deben retrotraernos a suponer que estamos analizando estructuras defensivas de carácter meramente romano, sino que su construcción y disposición estaba ya muy difundida, al menos en el período helenístico, y cualquier buen general los usaba como garantes de la seguridad de su campamento (Polibio, III, 100, 4-8). Hay que reseñar que en la guerra no todos los contendientes se guían por los mismos patrones a la hora de guarnecerse tras unas estructuras defensivas; hay elementos comunes que todos los pueblos conocen y usan en su beneficio. En el arte de la fortificación el pueblo romano desempeñaba el papel de batuta de la orquesta, ya que a las estructuras defensivas básicas de los asentamientos castrenses les irá añadiendo nuevos operativos que darán al campamento la apariencia de una auténtica ciudad fortificada (muchas de las modificaciones y adecuaciones acometidas son adaptaciones de pueblos con los que los romanos combatieron).

Uno de los cometidos de los fosos era el de evitar el acceso directo hacia la empalizada y las puertas. Por medio de su disposición se pretendía que el enemigo acometiese el asalto orientando el ataque hacia la izquierda, de modo que su parte 
derecha, al no estar protegida por el escudo, quedase al descubierto y los convirtiese en blancos fáciles. Llegado el turno de asentar el terraplén e hincar la empalizada, ambos elementos debían guardar relación con la propia magnitud de la construcción, siempre de un modo razonable, para dar al conjunto una imagen de equilibrio y seguridad.

Podemos señalar que la realización de los fosos sería, en cierta medida, más fácil que el resto del entramado defensivo, ya que para su acometimiento los soldados sólo debían portar las herramientas precisas para excavarlo ${ }^{11}$. Con ello no pretendemos decir que la construcción de las trincheras fuera sencilla, ya que en muchas ocasiones las mismas no pudieron ser llevadas a cabo debido a que el terreno no lo permitía (superficie rocosa, capas pedregosas, tierra demasiado blanda cuyo colapso era constante e inmediato, etc.). Siendo un pueblo de grandes ingenieros los romanos siempre trataban de hallar soluciones a los problemas con los que se encontraban; por lo que nos hemos encontrado con recintos donde estas, a priori, dificultades, fueron superadas con el esfuerzo conjunto del grupo legionario: se excavan trincheras en la propia roca ${ }^{12}$, se revisten los fosos de arcilla en aquellos lugares donde el terreno es muy suelto, logrando dotar las paredes del mismo de consistencia y evitando su hundimiento; etc.

A la hora de hablar del trabajo acometido por los soldados en los fosos, debemos destacar que en la actualidad existen equipos de investigación que tratan de arrojar luz, desde el terreno de la práctica, sobre el proceso de excavación de las trincheras que circunvalaban los castra romanos. Estos investigadores proponen que a la hora de acometer la excavación del foso se debía trazar una línea, que servía a los soldados de base y guía al señalar el lugar por el que debería discurrir. Seguidamente los soldados procedían a la extracción de la tierra en torno al eje central de la citada línea. Una vez que esto había sido llevado a cabo, se construían los lados del foso, de acuerdo con la profundidad y la inclinación que se quisiera

${ }^{11}$ En contraposición la empalizada requería tanto de herramientas como de materia prima con la que trabajar. Un estudio en torno al tipo de útiles que componían el equipo legionario podemos descubrirlo en ADAM, J. P. (2002): La construcción romana. Materiales y técnicas, León; GINOUVÈs, R. y MARTín, R. (1985): Dictionnaire méthodique de l'architectures grecque et romaine. I. Matériaux, techniques et formes du décor, École Française de Rome et d'Athènes, Roma-Atenas; LEWIS, M. J. T. (2001): Surveying instruments of Greece and Rome, Cambridge; etc.

12 Una manera de cortar la roca nos la transmite el propio Livio: "como fuera preciso cortar el peñasco, abaten y trocean árboles gigantescos de los que había por el contorno y hacen un enorme rimero de leños; habiéndose levantado un viento impetuoso apropiado para alimentar fuego, prenden el rimero, y, vertiendo vinagre sobre la roca ardiente, la desintegran" ( $A b$ urbe, XXI, 37, 2). 
dar al mismo y, teniendo en cuenta que la composición del terreno no siempre permitía alcanzar la profundidad deseada.

Los romanos, como buenos conocedores del terreno, estaban dispuestos a sacrificar la profundidad de los fosos en aras de mantenerlos en condiciones perfectamente optimas; de nada les servía un foso que estuviera anegado de tierra o cuyas paredes no se mantuviesen en pie, ya que su colapso llevaba aparejado un gran número de problemas y además les suponía un riesgo innecesario, ya que si éstos se hundían sería muy fácil para el enemigo atravesarlos, con lo cual el campamento se quedaría sin una de las líneas de defensa más importantes que poseía y ofrecería al enemigo un punto débil para atacarlos.

\section{TIPOLOGÍA Y TEORÍA}

Higinio nos habla de la existencia de dos tipos de fosos asociados a la erección de los recintos castrenses de adscripción romana: la fossa fastigata y la fossa Punica (fig. 1). En torno a la primera, podemos señalar que se trataría de un foso cuya sección se ajustaría a una forma en $\mathrm{V}$, siendo este el perfil que más comúnmente ha sido encontrado asociado a los campamentos; en relación al segundo tipo, la fossa Punica, podemos decir que estaba compuesta por una cara exterior con bastante pendiente (en algunos casos casi constituyendo una pared vertical), siendo en su interior la inclinación de la misma mucho más suave.

El fondo de algunos fossae fastigata se dotaba de un pequeño y estrecho canal. La función del mismo no podemos conocerla con seguridad, pero postulamos dos teorías en torno a su posible uso:

a) Se trataría de un nuevo obstáculo añadido para entorpecer a los enemigos que se atrevieran a intentar rebasarlo; el nombre que se le ha dado es, tan gráfico como el de "codos rompedores", ya que al llegar al fondo del foso, el canal serviría como elemento que provocaría torceduras y roturas de tobillo, que impedirían a los posibles asaltantes proseguir con su intento.

b) Sería un canal realizado para el desagüe y drenaje del foso, tesis con mayor valor y basada en criterios a priori más tangibles; pues entre los pápiros encontrados en Egipto y Siria se ha descubierto que en algunos de ellos se recogen las listas de deberes de los campamentos y uno de los mismos era llevar a cabo, con regularidad, la limpieza de los fosos. Este elemento podría haber sido creado de forma no intencionada, sino que sería el resultado de la labor sucesiva y continuada de la pala por el fondo de los mismos durante las limpiezas periódicas para librarlos de la vegetación y el sedimento. A fuerza de repetir esta misma acción daría paso a la presencia de esta marca característica. 
Este tipo de foso, a simple vista, nos ofrece una sensación de simetría perfecta, pero hemos de reseñar que esto no es así, ya que sobre el terreno es prácticamente imposible dar a ambos taludes inclinaciones idénticas. Son muy similares, pero con presencia de mínimas divergencias, ya que en la realización de los mismos hemos de contar con el terreno en el cual nos movemos, la cota que posea y las características del nivel geológico.

En algunas excavaciones ha sorprendido a los arqueólogos el hecho de encontrar fosos cuyo trazado no se ajustaba a ninguno de los dos tipos anteriormente citados, sino que en ellas han aparecido perfiles en forma de $\mathrm{W}$, lo que ha llevado a los investigadores a plantearse nuevas incertidumbres: ¿fueron originalmente excavados siguiendo este nuevo tipo de perfil o representan la unión de varios fosos del tipo fossa fastigata, cuyos posteriores recortes y acondicionamientos sobre el terreno llegaron a hacer que dos de los mismos se unieran dando lugar a este nuevo modelo?. Nos inclinamos más por esta segunda teoría, ya que la presencia de fosos con forma en $\mathrm{W}$ no nos viene indicada por ninguna de las fuentes antiguas con las que contamos, hemos de decir que ambas son hipótesis y que, por el momento, ni podemos descartar ni probar ninguna de ellas.

Ofreciendo datos estadísticos podemos señalar que, generalmente, la anchura de los fosos variaba entre los 2,5 y los 6 metros (9-20 pies), siendo lo más común que en los campamentos protegidos sólo por un foso la anchura del mismo se encontrase entre los 3,7 y los 5 metros (13-17 pies). A medida que el número de fosos iba en aumento (defensa con doble foso o con un sistema múltiple) la tendencia del tamaño de los mismos se iba reduciendo y haciéndose ligeramente más pequeña, aunque no siempre ocurría así.

Muchas veces a la hora de acometer trabajos arqueológicos en torno a las estructuras defensivas de un asentamiento de carácter militar se ha de tener en cuenta que vamos a encontrarnos con un gran número de problemas, para muchos de los cuales no se dispone de solución. A la hora de estudiar las trincheras que circunvalan muchos de estos recintos se documenta el inconveniente de que no podemos llegar a conocer con total exactitud y precisión la profundidad original de las mismas, ya que en muchas ocasiones su parte superior no ha sido conservada (destrucción por tareas agrícolas, asentamientos posteriores, etc.). Estas alteraciones nos dejan ante la tesitura de que sólo podemos conocer la base de la fosa, siendo del todo imposible reconstruir su profundidad exacta.

Otro dilema al que nos debemos enfrentar a la hora de llevar a cabo un estudio riguroso de los fosos es el hecho de que muchas veces los mismos pudieron ser 
profundizados, posteriormente a su original excavación, debido a la necesidad de nuevo material que añadir a la rampa (el cual se obtenía, en la mayor parte de los casos, de la excavación de las fossae), o reducidos en la misma, por la acumulación de sedimentos y escombros. La reducción de su profundidad nos parece, hoy en día, menos probable; ya que como hemos señalado anteriormente, entre las tareas de los soldados se encontraba la de llevar a cabo una limpieza de los mismos, lo cual haría poco probable que los escombros llegasen a acumularse tanto como para provocar su reducción.

No podemos hacer una generalización en torno al número básico de trincheras que podían rodear un asentamiento. En la erección o no de las mismas existían una amplia variedad de condicionantes, como hemos venido apuntando. En cuanto a su número máximo, podemos jugar con conjeturas, pero no podemos establecer una hipótesis totalmente fiable y contrastada; cada recinto era único y el número de fossae dispuestas en torno al mismo variaba de uno a otro con pasmosa facilidad; a modo de ejemplo señalaremos el fuerte de Whitley Castle $^{13}$, situado en el norte de Britannia, donde a través del trabajo de campo se ha documentado la presencia de siete fosos en uno de sus lados.

La "profundidad" del sistema de defensas, es decir, el espacio existente entre la parte exterior del terraplén y la zona más externa de los fosos, venía determinada por el alcance que tuvieran los proyectiles arrojados desde el interior de la guarnición. Esto es, el terreno de defensa en torno al campamento se encontraba diseñado en función de la eficacia que pudieran tener los hombres y las máquinas de artillería que se encontrasen dentro del recinto marcado como área castrense. Podemos señalar que la superficie que podrían ocupar estas defensas en profundidad se encontraría en torno a los 60-65 pies romanos, es decir, aproximadamente entre los 18 y los 19,50 metros, extensión abarcada a partir de la cara externa del terraplén. Teniendo en cuenta que esta distancia puede verse aumentada o reducida en función del armamento arrojadizo de que disponga la legión que ocupa el campamento. En la zona de la antigua Germania Superior, la mayoría de los ejemplos estudiados se mueven en torno a los 18 metros; mientras que en Britannia nos encontramos con dos grupos de asentamientos bien diferenciados, unos en torno a los 18-21 metros y otros alrededor de los 27-30 metros, reflejando la existencia de distintas clases de armamento al servicio de la

${ }^{13}$ Construido en torno al año 80 d. C., se encuentra situado sobre una pequeña colina, el fuerte se ajusta a un perfil en forma de diamante, en orden a alcanzar las mayores ventajas posibles sobre el terreno. A las defensas naturales con las que estaba dotado se ha de añadir el masivo sistema de fosos dispuesto en torno a todo su perímetro, sobresaliendo el lado noroeste con la presencia de 7 trincheras, debido a que este punto era el más débil de todo el trazado. 
guarnición. En el caso de Hispania, no hemos podido, hasta el momento y basándonos en los datos que poseemos, establecer un promedio claro, pues no se conoce con precisión el entramado defensivo de que estaban dotados los castra que tenemos documentados. Esperamos que el desarrollo de posteriores trabajos sobre los mismos arroje cifras indicativas en torno a esta cuestión.

\section{HISPANIA: FOSILIZACIÓN DE DOS SIGLOS DE LUCHA}

República e Imperio romanos estuvieron presentes en nuestro suelo. Los habitantes del Tíber habían descubierto que el crecimiento y mantenimiento de su prosperidad emanaba, en gran parte, de todos aquellos recursos que llegaban desde las más diversas partes de sus extensos dominios. Hispania se convierte en el 218 a. C. en un nuevo objetivo. Conquistarla no fue tarea fácil, los relatos transmitidos por los autores antiguos están plagados de los constantes y continuos enfrentamientos acaecidos entre romanos e indígenas. No será hasta el año 19 a. C., con la llegada de Augusto a la Península y la derrota de cántabros y astures, cuando se pueda afirmar que estos nuevos terrenos pasaban a integrar en su totalidad parte de un imperio inabarcable.

El mejor testimonio de la duración, dificultad, lucha $\mathrm{y}$, finalmente, incorporación de la piel de toro bajo la bota romana nos la arrojan la gran cantidad de castra cuya documentación tenemos constatada a lo largo y ancho de toda la Península. Hemos de tener en cuenta que Hispania "puede ser considerada como un limes sin frontera, marcaba el límite del imperio por su parte oeste, pero no se enfrentaba a la amenaza de pueblos limítrofes ni a posibles invasiones procedentes de allende de los mares, por lo que el amplio dispositivo desarrollado en los limes germano y britano se hizo aquí totalmente innecesario, cuestión que, a priori, podría dejarnos fuera del estudio de los asentamientos castrenses" (Morillo, 1996). Claramente, los trabajos e investigaciones sobre Hispania presentan un gran retraso y dependencia frente a los desarrollados en el resto de los límites del imperio; pero, los últimos años han sido prolíficos en cuanto a la identificación de nuevos asentamientos, hallazgos fortuitos y estudios en profundidad de los castra ya conocidos. El impulso dado por el II Congreso de Arqueología Militar Romana en Hispania (octubre del 2004) y el XX International Congress of Roman Frontier Studies (septiembre del 2006), ambos celebrados en León, ha logrado poner de relevancia la importancia de los trabajos que se vienen acometiendo por muchos y muy buenos investigadores en nuestro país, así como ha ayudado a romper una lanza a favor del estudio de elementos arquitectónicos, factores estratégicos, capacidad de visión, etc. desarrollados y puestos en escena en nuestro suelo por los romanos. 
El sistema de guerra utilizado por los romanos respondía a un estilo muy agresivo, siendo sus campamentos auténticas fortalezas ambulantes. Al hacer frente y tomar parte en diversidad de conflictos armados estaban acostumbrados a tomar la iniciativa lo antes posible y a mantener una presión constante sobre el enemigo, hasta quebrar su voluntad de lucha. Un estudio conjunto del proceso de conquista de Hispania en relación con la distribución de los asentamientos castrenses a lo largo de la Península nos mostraría de manera clara y fehaciente la clara realidad que se enmascara tras esta afirmación. De este modo consiguieron la mayoría de sus éxitos. Los romanos no admitían la posibilidad de ser derrotados y ni siquiera cuando recibían serios reveses o su posición militar era desesperada capitulaban. La obstinada y expresa renuncia a admitir la derrota - una característica romana que persistió hasta bien entrada la tardo-antigüedad- hacía muy difícil que Roma perdiese alguna guerra. Además hay que tener en cuenta que si hubiesen reconocido sus fracasos el honor de la ciudad del Tíber hubiera quedado en entredicho, algo que sus ciudadanos no podían permitir.

En la actualidad se tienen documentados en torno al medio centenar de posibles asentamientos romanos de carácter castrense en la Península; muchos aún pendientes de su correcta atribución, al mismo tiempo, que muchos otros, en espera de ser descubiertos e identificados. No podemos obviar el hecho de que hay una gran multitud de castra de los que nunca tendremos noticias, ni podremos documentar su presencia: existieron, pero su brevedad y el carácter perecedero de los materiales que los constituían no han dejado huellas de su presencia sobre el terreno. No debemos olvidar que la fosilización de estas estructuras conllevaba aparejado un período de tiempo mayor al asociado a los campamentos de marcha, cuya función de lugar de pernocta para los ejércitos durante escasos días no permite encallecer su rastro y, por tanto, nos impide rastrear su existencia ${ }^{14}$.

Entre los vestigios más destacados y fáciles de identificar sobre el terreno se encuentra nuestro objeto de análisis: los fosos. Los movimientos de tierras, así como su cambio de coloración y su factible identificación a través de la fotografía aérea son elementos que nos han permitido tipificar y clarificar la filiación de numerosos restos, estructuras y asentamientos como de clara función castrense. El tamaño, su ubicación geográfica, la distribución en torno a los reales, su perfil, etc. son claros indicadores de la gran diversidad que presentan y nos ponen de relieve la

\footnotetext{
14 Teniendo en cuenta las peculiaridades geográficas, climáticas y edafológicas de los suelos de la península ibérica resulta muy difícil la identificación de las estructuras que conforman el entramado de los recintos castrenses, ya que no existen garantías de conservación, supervivencia y preservación de los elementos que nos llevarían a identificar este tipo de asentamientos.
} 
adaptación del soldado romano a cualquier campo de acción, circunstancia o enemigo. Los soldados romanos eran temibles en la batalla campal, pero eran insuperables en la guerra de pico y pala, se seguía el principio romano "sedendo romanus vincit" (el romano vence sentado). Buscar la rendición del adversario por medio del bloqueo, mejor que por las armas, es un método eficaz y típicamente romano.

Hispania nos ha legado un amplio número de asentamientos castrenses, un pasado dormido bajo nuestros pies comienza a surgir de nuevo a la vida. Un idílico panorama que se ve frenado debido al hecho de que identificación, excavación, investigación, documentación y publicación no sean acciones que vayan de la mano en los trabajos llevados a cabo en nuestro suelo. Carecemos, en la actualidad, de un conocimiento completo en torno a la mayoría de los recintos cuyos nombres y estructuras van a servir como referentes en nuestro trabajo; no han sido excavados en su totalidad, el material recogido (documentado en el mejor de los casos) no ha sido estudiado ni puesto en valor, etc. Una fuente inagotable de información sigue vegetando en numerosos y dispersos laboratorios de nuestro país. No demos sólo una visión pesimista en relación a este tema, pues las intervenciones realizadas y los trabajos llevados a cabo en la actualidad en la mayoría de estos recintos nos han permitido gozar de un gran caudal de información, que lejos de agotarse comienza a mostrar unos bríos que esperemos sigan creciendo en años venideros.

De los asentamientos castrenses documentados en suelo peninsular se ha podido consignar de manera fehaciente y sin lugar a dudas la presencia de foso en más de una treintena de ellos; no existiendo un criterio uniforme en torno a tamaño, extensión, perfil, número, etc. Cada asentamiento es único y sus elementos defensivos adquieren el señero mérito de corresponder a este principio en función de la naturaleza, el arte, puntos débiles, enemigos, tiempo, tipo de tierra, carácter del acuartelamiento, etc. No hay distinción en torno a su cronología, pues se ha prestado igual atención a los de carácter republicano y a los de época imperial, tampoco en relación al carácter geográfico, ya que el recinto romano seguía unos principios básicos de edificación y de adecuación al entorno en el cual se asentaban, jugaba un papel destacado el ojo del general, así como su capacidad de adaptación y aprovechamiento del medio, la dirección del ejército, su confianza en la victoria, la estrategia diseñada, etc. (fig. 2 y 3 ).

Excavar la trinchera era el primer trabajo llevado a cabo a la hora de asentar los reales. Predominan en la península ibérica los campamentos con un solo foso (en torno a la veintena) frente a los de un sistema múltiple (apenas llegan a la decena), sin olvidarnos de aquellos en los que no se ha documentado la presencia de 
ninguno (por no conocerse aún el recinto en toda su extensión; por haber desaparecido sus huellas bajo el progreso de la civilización; por la naturaleza de su asentamiento que los hacía innecesarios; etc.). El tamaño de los mismos oscila entre los 30 y los 2 metros de extensión. El primer ejemplo documentado para el potente foso que circunvala el recinto de La Cabañeta (El Burgo de Ebro, Zaragoza), el cual se ajusta a un perfil en forma de W, lo cual reduce la dilatada amplitud citada para este sistema de posible doble trinchera, destacando el hecho de que el resultado de las excavaciones de este asentamiento todavía no se ha publicado, por lo que no podemos aseverar con toda seguridad el espacio que comprende ni darle un carácter militar definitivo; mientras que es en Cáceres el Viejo (¿Castra Caecilia?, Cáceres) donde el sistema de doble foso nos señala una anchura de 2 metros para el más externo de los mismos, fluctuando el interior entre los 3-4 metros.

Trabajamos con cifras indicativas y con una gran carencia de datos en torno a muchos de los asentamientos estudiados, pues, a pesar de la documentación, constancia y pervivencia de estos elementos no han sido excavados, medidos ni han dejado huellas patentes de anchura y profundidad, por lo que solo a través del trabajo de campo se puede llegar a conocer las mesura de los mismos. En ocasiones, solo podremos hacer referencias a la presencia de foso en todo o en parte de su perímetro, pero sin hacer saltar a la palestra datos y cifras de referencia ${ }^{15}$.

En relación al perfil con carácter predominante en este tipo de asentamientos se puede resaltar paridad en la utilización de los mencionados en la obra de Higinio, sobre todo la conocida fossa fastigata, la silueta con forma de $\mathrm{V}$ aparece, entre otros, en Alto do Castelo (Alpiarça, Ribatejo, Portugal), Los Cascajos (Sangüesa, Navarra), Ses Salines (Mallorca), Cáceres el Viejo (Cáceres), Astorga (León), Baños de Bande (Ourense), El Cantón (Molledo y Arenas de Iguña, Cantabria), El Cincho (La Población de Yuso, Cantabria), León, Rosinos de Vidriales (Zamora), etc. Se ha documentado como protección de algunos reales el hecho de que se ha dragado el terreno en un trazado en forma de $\mathrm{U}$, tal como podemos observar en

${ }^{15}$ Adolecemos la falta de este tipo de información, pero es comprensible desde el punto de vista de la falta de medios, financiación, trabajo continuado, etc. de que carecen estos recintos, teniendo en cuenta que la arqueología es una ciencia relativamente joven y que ha sido muy recientemente cuando se ha producido el despegue y valoración del importante papel jugado por nuestro suelo no podemos por menos que sentir que comenzamos a recorrer un camino largo y duro, pero, a buen seguro, repleto de futuros éxitos. 
Alto do Castelo, Cáceres el Viejo, Cotero del Medio (Luena, Cantabria), etc. ${ }^{16}$ Tampoco hemos de obviar la mención al contorno con grafía de $\mathrm{W}$, presente en $\mathrm{La}$ Cabañeta. Hay que tener en cuenta para este tipo de trazado lo señalado con anterioridad en torno a la posible unión de un sistema de fosos múltiple tipo fossa fastigata que darían marca de identidad y nacimiento a este esbozo.

Si escasas son las cuantificaciones en torno a la anchura del trazado de las trincheras podríamos señalar que las variables con las que contamos para estudiar y valorar la profundidad de las mismas es prácticamente inexistente. En la actualidad, la península ibérica sólo nos señala exiguos asentamientos donde podamos conocer con exactitud la sima de las mismas, estos son: Los Cascajos (Sangüesa, Navarra) con un foso de 10 metros de anchura y 2 de profundidad; Ses Salines (Mallorca) cuyo perfil en V nos marca una mayor hondonada que amplitud, $3,50 \times 3,20$, respectivamente; y, Astorga (León), cuyo doble foso, nos presenta un foso exterior con un perfil más abierto y menos profundo, pero con una marcada disimetría entre ambos taludes (siendo el interno el más pronunciado), ajustado a unas medidas oscilantes entre los 3,50 y los 2,20 metros de anchura y los 1,85-1,20 de profundidad, presentando el foso interior 2,40 metros de calado, al mismo tiempo que muestra un talud exterior perfectamente cortado en declive ${ }^{17}$.

Cada situación, cada enfrentamiento, cada enemigo, cada victoria, cada día de la historia del mundo romano era único, como únicos eran sus asentamientos. Aún contando con las pautas iniciales que debían regir y guiar la construcción de los reales, la edificación, la naturaleza, la estrategia, el general y los soldados eran los encargados de dar a cada una de sus creaciones la cualidad de ser únicas. No hay dos construcciones iguales: semejantes, sí, idénticas, no. Pongamos ejemplos de lo que acabamos de señalar:

- Almazán (Soria), presenta restos de un foso en su lado oeste, cuyas medidas no han podido ser documentadas por las destrucciones causadas por una cantera de grava y una repoblación de pinos.

${ }^{16}$ No debe llamarnos la atención el hecho de que Alto do Castelo (Alpiarça) y Cáceres el Viejo hagan acto de presencia en ambas clasificaciones, pues se trata de dos campamentos con un sistema defensivo de doble foso, cada uno de los cuales se ajustaba a los patrones que acabamos de reseñar, llamando la atención de que en Alpiarça la silueta en U pertenece al perfil del foso exterior y la de $\mathrm{V}$ al más interior, hecho que en Cáceres aparece de forma reversible, es decir, la fossa fastigata es la que ocupa la parte externa de su doble entramado.

${ }^{17}$ La excavación parcial llevada a cabo en el mismo no nos permite señalar su anchura. 
- Alto do Castelo (Alpiarça, Ribatejo, Portugal) muestra los restos de un agger romano completo, con un sistema en doble foso, ajustado a un perfil en $U$ en el externo y uno en $\mathrm{V}$ para el más interior.

- Andagoste (Cuartango, Álava), un campo de batalla fortificado a toda prisa ante un asedio indígena, muestra trazas de un foso de fondo plano tallado en suelo rocoso.

- Ses Salines (Mallorca), donde el trazado del recinto no ha podido documentarse completamente al estar bajo construcciones actuales, presentando una fossa fastigata con una anchura de 3,20 metros, sobrepasados en $30 \mathrm{~cm}$ por la profundidad de la misma.

- Navalcaballo (Soria), donde se creen reconocer los vestigios de un agger completo asociado a obras militares de carácter defensivo, el cual se dispondría en dos largos surcos paralelos que eran respaldados en su interior por una loma ancha y aplastada, la diferencia existente entre el fondo del surco y la zona más alta de la loma es de en torno a 60-80 cm, aunque el estado de conservación de estos restos no es demasiado bueno ${ }^{18}$.

- Cáceres el Viejo (¿Castra Caecilia? ${ }^{19}$, cuyas construcciones presentan una gran solidez, calidad y lujo, su recinto se halla acotado por un doble foso, con un intervalo de 2 metros entre los mismos, siendo el más externo de 2 metros de anchura y perfil en $\mathrm{V}$ y el interno, a 2 metros de la muralla, con un esbozo en $\mathrm{U}$ y entre los 3-4 metros de amplitud.

- Numancia (Garray, Soria), cuya circunvalación se encuentra respaldada totalmente por un foso de en torno a los 10 metros de anchura.

18 Taracena y García y Bellido lo consideran como un castra aestiva asociado al desarrollo de las guerras sertorianas, aseveración que no podemos asegurar con total fiabilidad, por lo que nos limitamos a reseñar las características por las que ha sido incluido en el estudio y dejamos en suspenso si la datación y la atribución reseñada se ajustan o no a la realidad.

${ }^{19}$ Este recinto es objeto de una gran polémica en torno a la fecha concreta de su erección y se han planteado toda una serie de alternativas en cuanto a su posible identificación, como su equiparación con el Castra Servilia o el Castra Liciniana que aparecen citados en las fuentes. El estudio y valoración del mismo por parte de Ulbert supone el despegue del estudio de la arqueología militar romana en la Península, gracias a los planteamientos teóricos y la metodología arqueológica que desarrolla en el mismo (ver ULBERT, G. (1984): Cáceres el Viejo. Ein spätrepublikanisches Legionslager in Spanisch-Extremadura, Madrider Beiträge XI, Mainz). 
- Astorga (León), al cual nos hemos referido con anterioridad, con la singularidad de contar en el fondo de los mismos con la ranura denominada "codos rompedores".

- La Carisa (Asturias) donde 2 ó 4 fosos, según la zona, protegen el recinto.

- Cildá (Corvera de Toranzo y Arenas de Iguña, Cantabria) con un sistema de fosos dobles (fossa duplex).

- La Poza (Campoo de Enmedio, Cantabria) con sus defensas excavadas directamente sobre la roca.

- León, foso en V siguiendo una dirección este-oeste, tallado sobre un substrato natural de gravas y con una amplitud variable entre los 5 y los 6 metros, consecuencia de que la parte superior del límite septentrional del foso no ofreciese un perfil rectilíneo, abriéndose ligeramente a partir de su mitad este (García Marcos, 2005).

- Rosinos de Vidriales (Zamora), cuyo doble asentamiento, primero por la Legio $X$ Gemina nos lega un sistema de fosas semejante al de Astorga y, posteriormente, el Ala II Flavia adecua su estructura a un sistema de fossa fastigata de 4 metros de ancho por uno de profundidad; etc.

A lo largo del presente trabajo hemos mencionado en diversos lugares el importante y destacado papel jugado por una correcta elección del terreno, ya que cuando un asentamiento no era fuerte por naturaleza se ponía remedio a sus debilidades por medio del arte, trabajo en el que enmarcamos la excavación de las trincheras. En la extensión de nuestra Península y en relación a los diversos tipos de construcciones castrenses que tenemos documentadas hemos de señalar que existen pocos recintos en los que, hasta el momento, seamos conscientes de la existencia de un foso que los circunvale en toda su amplitud, la mayoría de los ejemplos estudiados desplegaron este tipo de sistema en aquellos puntos o zonas más débiles o susceptibles de ataques enemigos ${ }^{20}$. Ilustrando nuestra aseveración con una muestra de las evidencias arqueológicas que poseemos: Almazán (Soria) y Baños de Bande (Ourense) presentan restos en su lado oeste; Castelo da Lousa (Alpiarça, Portugal) por el sur; El Castillejo (Pomar de Valdivia, Palencia) en su

${ }^{20}$ A destacar es el hecho de que no podemos conocer con exactitud la extensión y amplitud de este elemento en torno a una gran mayoría de los recintos mencionados, pues la excavación de los mismos se ha realizado de manera parcial y no contamos con datos precisos en el sentido de permitirnos fijar con precisa coherencia la situación de los mismos. 
parte suroeste y en el ángulo sur del recinto; Valdemeda (Manzaneda, León) en sus ángulos noroeste y suroeste y en el lado sur; etc.

El resto de asentamientos de los que nos hemos venido haciendo eco presentan, hasta el momento, carencias en cuanto a una afirmación en este sentido, pues las publicaciones nos hablan de la existencia de los mismos pero no nos han definido con precisión su ubicación, extensión y función estratégica. También contamos con un dilatado número de asentamientos para los cuales no se tiene constancia arqueológica de la presencia de foso, bien por su mal estado de conservación, por su destrucción parcial o por la falta de trabajos de campo, entre los que podemos señalar las construcciones de Lomba do Canho (Arganil, Portugal), Alpanseque (Soria), Las Chões de Alpompé (Santarém, Ribatejo, Portugal), Muro de Ágreda (Soria), Atxa (Vitoria, Álava), Castrocalbón (León), Villalazán (Zamora), etc.

No quisiera acabar sin antes llamar la atención sobre un hecho importante en el desarrollo del proceso de conquista del suelo peninsular, la guerra sostenida por Augusto en orden a someter y poner bajo la órbita romana a cántabros y astures nos ha legado un importante y amplio abanico de asentamientos de carácter castrense en las estribaciones del noroeste (Cantabria y Asturias, principalmente), a destacar El Campo de las Cercas (Puente Riesgo y San Felices de Buelna, Cantabria); El Cantón (Molledo y Arenas de Iguña, Cantabria), castellum asociado a La Espina del Gallego (Corvera de Torenzo y Arenas de Iguña, Cantabria), rodeado por fossa fastigata; La Carisa (Asturias), que cuenta con un sistema defensivo muy desarrollado y 2 ó 4 fosos según la parte de su línea que sigamos; Cildá (Corvera de Toranzo y Arenas de Iguña, Cantabria), con un sistema de fossa duplex; El Cincho (La Población de Yuso, Cantabria), sistema de trinchera esbozada en V; Cotero del Medio (Luena, Cantabria), fortificación con una gran fosa en forma de $\mathrm{U}$ en su parte sur, destacando un desnivel de unos 10 metros entre lo alto del terraplén y el fondo de la trinchera, quizá en relación con el deseo de frenar el avance de los cántabros; La Loma (Palencia), fuerte dentro de un anillo de cerco, en la parte norte del circuito se ha hecho patente la existencia de un segundo foso al ser la zona más accesible al enemigo; Valdemeda (León), trabajos mineros han dañado algunas de las trazas dejadas por los fosos; etc.

A menudo se añadía al sistema de defensa de las fossae todo un despliegue de obstáculos destinados a incomodar e importunar a los asaltantes. La disposición de los mismos se realizaba tanto dentro como más allá del sistema de trincheras, requería el empleo de más tiempo y nuevos trabajos para los legionarios, pero la protección que proporcionaban compensaba el esfuerzo. Además, al añadir estas trabas la vigilancia de las trincheras podía ser cubierta con un menor número de soldados. Entre estos subterfugios podemos encontrarnos con el uso de cercos 
hechos con materiales llenos de espinas, estacas afiladas y lanzas hincadas en la tierra, cepos, abrojos, lirios, salchichones ${ }^{21}$, rejones, zarzas, ramas, etc. Hemos de señalar que todos estos obstáculos son casi imposibles de rastrear, ya que normalmente, al tratarse de materiales perecederos, dejan muy pocas o ninguna evidencia arqueológica. Sólo terrenos empapados o con unas cualidades de conservación excepcionales pueden suministrar ejemplos con los que trabajar. Ahora bien, el uso de estas "estructuras defensivas" nos es conocido gracias a los escritores antiguos, muchos de los cuales en sus obras nos dan una detallada descripción de su uso en torno a los campamentos: César, De bell. Gall., VII, LXXIII; De bell. Afric., XXXI y De bell. Civil., I, XXVII; Frontino, I, V, 5 y II, III, 17.

Una de las grandezas del ejército romano era su capacidad de adaptación al terreno y a las circunstancias que le rodeaban. Por ello no podemos establecer un modelo prototípico que responda a nuestras necesidades. Cada asentamiento y el momento de erección que le rodeaba era único y como tal el resultado era distinto en cada caso. En la antigüedad ningún otro pueblo alcanzó el grado de perfección que lograron los romanos a la hora de asentar sus reales. Estas pequeñas porciones de tierra se convertían, sin importar el tiempo que estuvieran ocupadas, en una perfecta representación de la Urbe; dejando constancia de la disciplina y diligencia de la maquinaria legionaria.

Los romanos dominaban el arte de la guerra, pero ello no impedía que la ferocidad e ira de los pueblos atacados no los pusiera en grandes apuros. La guerra, a pesar de todos los ingenios y los avances técnicos, sigue siendo un enfrentamiento de hombres contra hombres en pos de la propia supervivencia, por lo que la desesperación y la rabia se convierten en armas muy poderosas, sobre todo cuando se lucha por la propia vida.

\title{
BIBLIOGRAFÍA
}

\section{Fuentes}

\author{
César, De Bello Gallico \\ De Bello Civile \\ De Bello Alexandrino \\ De Bello Africano
}

\footnotetext{
${ }^{21}$ Se trata de fajina grande formada con ramas gruesas, es decir, haces de ramas muy apretadas de que se servían los ingenieros militares para diversos usos, ver CALABRO, M. (1991): Tratado de fortificación o arquitectura militar, Salamanca, 126.
} 
De Bello Hispaniense

Floro, Epitome Gestae Romanae

Frontino, Strategemata

Higinio, De Metatione Castrorum o De Munitionibus Castrorum

Ovidio, Fastos

Polibio, Historias

Tito Livio, Ab urbe condita

Vegecio, Epitome Rei Militari

Vitrubio, De Architectura

\section{Bibliografía general}

ADAM, J. P. (2002): La construcción romana. Materiales y técnicas, León.

ALARCÃO, J. DE (1988): Roman Portugal, Warminster.

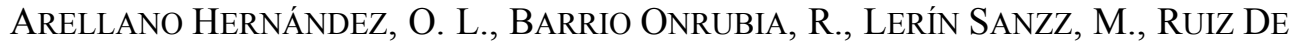
MARLO, A. y TARANCÓN GÓMEZ, M. J. (2002): "Sobre el origen campamental de Augustobriga (Muro, Soria)", en A. Morillo (coord.) Arqueología militar romana en Hispania, Anejos de Gladius 5, Madrid, 275-281.

ASENSIO ESTEBAN, J. A. (2003): "Urbanismo romano republicano en la región de la cuenca del Ebro (Hispania Citerior), 179-44 a. e.", AEspA 76, 159-178.

BLÁZQUEZ, J. M. (1999): "Campamentos romanos en la meseta hispana de época romano republicana", Las guerras cántabras, Santander, 65-118.

CAlabro, M. (1991): Tratado de fortificación o arquitectura militar, Salamanca.

DE LA TORRE ECHÁVARRI, J. I. (1998): "Numancia: uso y abusos de la tradición historiográfica", Complutum 9, 193-211.

Diogo, A. M. D. y TRINIDADE, L. (1993-4): Materiais provenientes dos Chões de Alpompé (Santarém), Conimbriga 32-33, 263-281.

FABIÃO, C. (2005): "Arqueología militar romana da Lusitania: textos e evidências materiais", C. Pérez-González y E. Illarregui (Coords.), Actas Arqueología militar romana en Europa (2001), Salamanca, 53-73.

Ferreruela, A., Mesa, J. F., Mínguez, J. A. y Navarro, M. (2003a): "Una inscripción republicana de la sede de una posible corporación en La Cabañeta (El Burgo de Ebro, Zaragoza): nuevos datos sobre la ocupación romana del valle del Ebro", AEspA 76, 217-230.

Ferreruela Gonzalvo, A. y Mínguez Morales, J. A. (2003b): "Dos modelos de implantación urbana romanorrepublicana en el valle medio del Ebro: las ciudades de La Cabañeta y La Corona", AEspA 76, 247-262.

GAMER, G. y ORTEGO Y FRIAS, T. (1969): "Neue Beobbachtungen am römischen Lager bei Almazán (prov. Soria)", Madrider Mitteilungen 10, 172-184.

GAMER, G. y ORTEGO Y FRÍAS, T. (1970): "Nuevas observaciones sobre el campamento romano de Almazán (Soria)", Celtiberia 39, 67-79. 
GARcía Y Bellido, A. (1976): "El ejército romano en Hispania", AEspA 49, 59101.

GARcíA MARCOS, V. y MORILlO, A. (2000/2001): "El campamento de la legio VII gemina en León. Novedades sobre su planta y sistema defensivo", Lancia 4, 103-126.

GARCÍA MARCOS, V. (2002): "Novedades acerca de los campamentos romanos de León”, A. Morillo (Coord.), Arqueología Militar Romana en Hispania, Anejos Gladius 5, Madrid, 167-212.

GARCÍA MARCOS, V. (2005): "Los campamentos de las legiones VI Victrix y VII Gemina en León", C. Pérez-González y E. Illarregui (Coords.), Actas Arqueología militar romana en Europa (2001), Salamanca, 167-195.

GARLAN, Y. (2003): La guerra en la Antigüedad, Madrid.

GINOUVÈS, R. y MARTÍN, R. (1985): Dictionnaire méthodique de l'architectures grecque et romaine. I. Matériaux, techniques et formes du décor, École Française de Rome et d'Athènes, Roma-Atenas.

GONZÁlez FERnÁnDEZ, M. L. (1994): "La fortificación campamental de Astvrica Avgvista", Cuadernos Municipales 3, Astorga.

JIMENO MARTÍNEZ, A. (2002): "Numancia: campamentos romanos y cerco de Escipión", AEspA 75, 159-176.

JONES, M. J. J. (1975): Roman Fort-defences to A. D. 117, with special reference to Britain, BAR 21, Oxford.

JOHNSON, A. (1983): Roman Forts, London.

KEPPIE, L. (1984): The making of the Roman Army, Londres.

LE BOHEC, Y. (2004): El ejército romano, Barcelona.

LEWIS, M.J.T (2001): Surveying instruments of Greece and Rome, Cambridge.

LlinÀs I POL, J., MERINO I SERRA, J., Miró I AlAiX, M. y PEDRÓN I PEDRÓN, Ma J. (1994): "El campament romà de Peralada: una fortificaciò d'època republicana al hinterland d'Empúries", Actas XIV Congreso Internacional de Arqueología Clásica (1993), Tarragona, 246-247.

MARTíneZ GÁZQUEZ, J. (1974a): La campaña de Catón en Hispania, Barcelona.

MASQuEleZ, E. (1887): "Castra" en Daremberg-Saglio: Dictionnaire des antiquités grecques et romaines, I, París, 940-959.

MORALES HERNÁNDEZ, F. (2000): "Una reinterpretación de la circunvalación escipiónica de Numancia", Revista d'Arqueologia de Ponent 10, 227-241.

MORALES HERNÁNDEZ, F. (2002): "La circunvalación escipiónica de Numancia: viejos y nuevos datos para una interpretación", A. Morillo (Coord.) Arqueología militar romana en Hispania, Anejos de Gladius 5, Madrid, 283-292.

MorAles HERnÁNDEZ, F. (2005): "Los campamentos y fuertes romanos del asedio de Numancia", C. Pérez-González y E. Illarregui (Coords.), Actas Arqueología militar romana en Europa (2001), Salamanca, 251-258. 
Morillo, A. (1991): "Fortificaciones campamentales de época romana en España", AEspA 64, 135-190.

MoriLlo, A. (1993): "Campamentos romanos en España a través de los textos clásicos", Espacio, Tiempo y Forma. Historia Antigua, serie II, 6, 379-397.

MORILlO, A. (1996): "Los campamentos romanos en la Meseta Norte y el Noroeste: ¿un limes sin frontera?", Coloquio Internacional sobre los Finisterres Atlánticos en la Antigüedad. Época Prerromana y Romana, Gijón, 77-83.

MoRILlO, A. (Coord.) (2002): Arqueología militar romana en Hispania, Anejos de Gladius 5, Madrid.

Morillo, A. (Coord.) (2003a): Defensa y territorio en Hispania de los Escipiones a Augusto, Universidad de León/Casa de Velásquez (2001).

MORILLO, A. (2003b): "Los establecimientos militares temporales: conquista y defensa del territorio en la Hispania republicana", en A. Morillo (coord.) Actas del coloquio sobre Defensa y territorio en Hispania de los Escipiones a Augusto (2001), Madrid, 41-80.

MoriLlo, A. (2005): "El ejército romano en la Península Ibérica. De la "arqueología filológica" a la arqueología militar romana", Estudios Humanisticos. Historia, 177-208.

Morillo, A. y AurrecoecheA, J. (eds) (2006): The Roman Army in Hispania. An Archaeological guide, Universidad de León.

OCHARAN LARrondo, J. A. y UnZueta Portilla, M. (2002): "Andagoste (Cuartango, Álava): un nuevo escenario de las guerras de conquista en el norte de Hispania", A. Morillo (Coord.), Arqueología militar romana en Hispania, Anejos de Gladius 5, Madrid, 311-325.

Pamment Salvatore, J. (1996): Roman Republican Castramentation. A reappraisal of historical and archaeological sources, BAR. Int. Series 630, Oxford.

Pina Polo, F. y Pérez Casas, J. A. (1998): "El oppidum Castra Aelia y las campañas de Sertorius en los años 77-76 a. C.", Journal of Roman Archaelogy $11,247$.

PINA POLO, F. (2003): "Introducción: el valle medio del Ebro entre el mestizaje cultural y la frontera militar", AEspA 76, 155-158.

REDDÉ, M. y SCHNURBEIN, S. von (Dir.) (2001): Alésia: fouilles et recherches franco-allemandes sur les travaux militaires romains autour du Mont-Auxois (1991-1997), París.

SalvatoRe, J. P. (1996): Roman Republican Castrametation, Oxford.

SÁNCHEZ-LA FUENTE (1979): "Aportaciones al estudio del campamento romano de "La Cerca" (Aguilar de Anguita, Guadalajara), Wad-al-Hayara 6, 77-82.

SCHUlten, A. (1937): Fontes Hispaniae Antiquae IV. Las guerras de 154-72 a. C., Barcelona. 
Schulten, A. (1940): Fontes Hispaniae Antiquae V. Las guerras de 72-19 a. C., Barcelona.

SCHUlten, A. (1945): Historia de Numancia, Barcelona.

SCHULTEN, A. (1949): Sertorio, Barcelona.

SHIRLEY, E. A. M. (2000): The Construction of the Roman Legionary Fortress at Inchtuthil, BAR 298, Oxford.

TARACENA, B. (1941): Carta arqueológica de España, Madrid.

TARACENA, B. (1947): “Arte romano: campamentos", Ars Hispaniae II, Madrid, 27-28.

TORRE, J. I. (1998): "Numancia: usos y abusos de la tradición historiográfica", Complutum 9, 193-212.

UlBERT, G. (1984): Cáceres el Viejo. Ein spätrepublikanisches Legionslager in Spanisch-Extremadura, Madrider Beiträge XI, Mainz.

WalbanK, F. W. (1975): "Polemic in Polybius", JRS 52, 1-12.

WILSON, R. (1980): Roman Forts. An Illustrated Introduction to the Garrison Post of Roman Britain, London. 

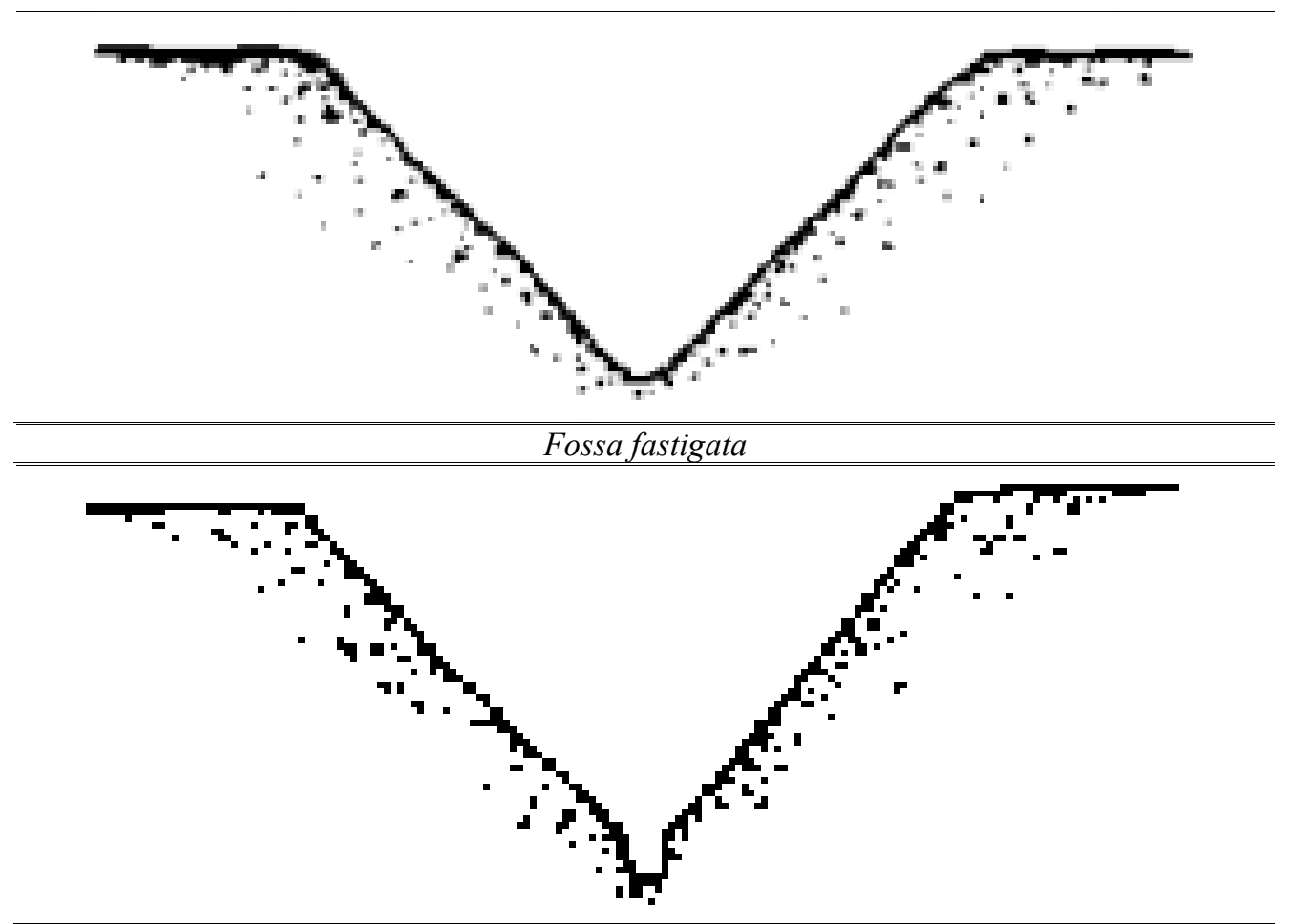

Fossa fastigata (con canal de desagüe)

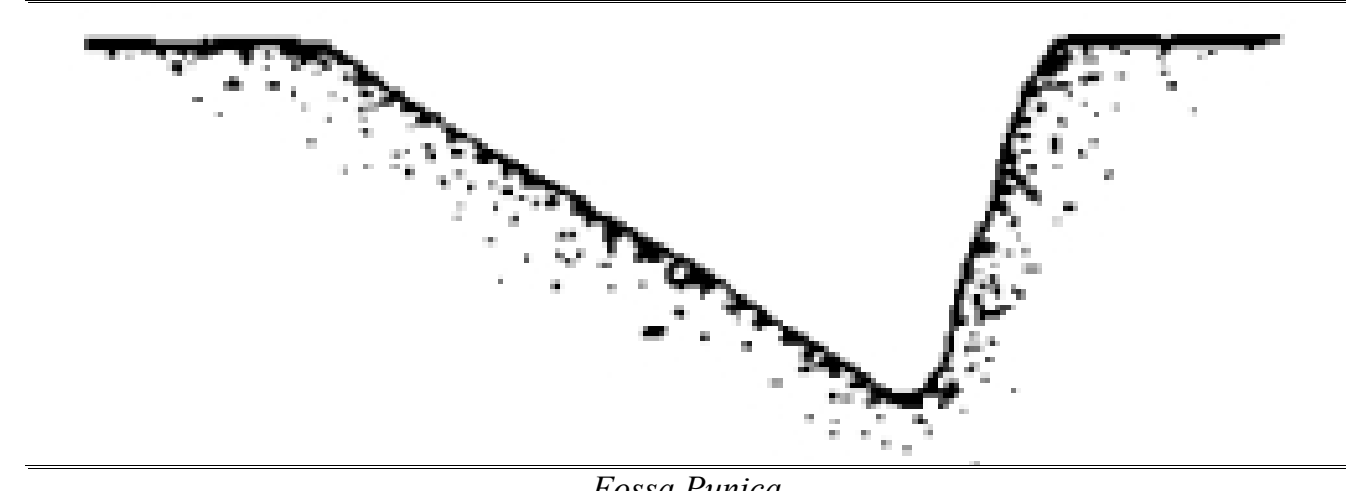

Fossa Punica

Fig. 1. Reconstrucción de los tipos de fosos usados en torno a los recintos campamentales (según Johnson). 


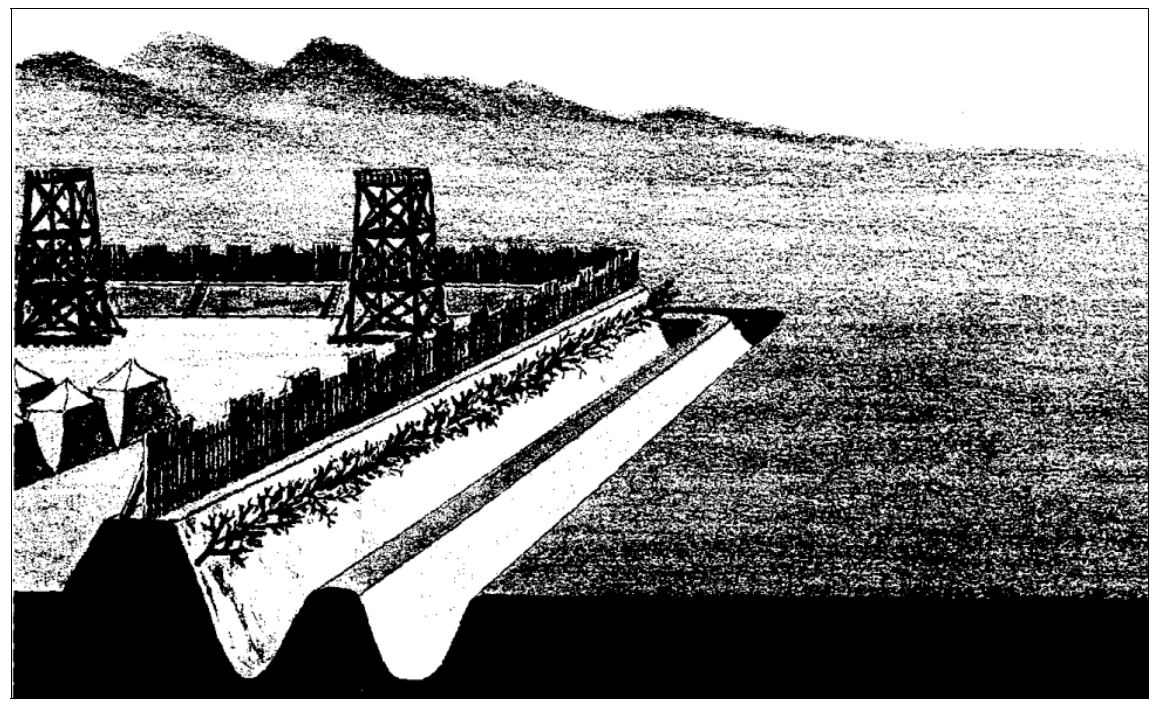

Fig. 2. Perspectiva axionométrica de las defensas de un castra aestiva (según González Fernández).

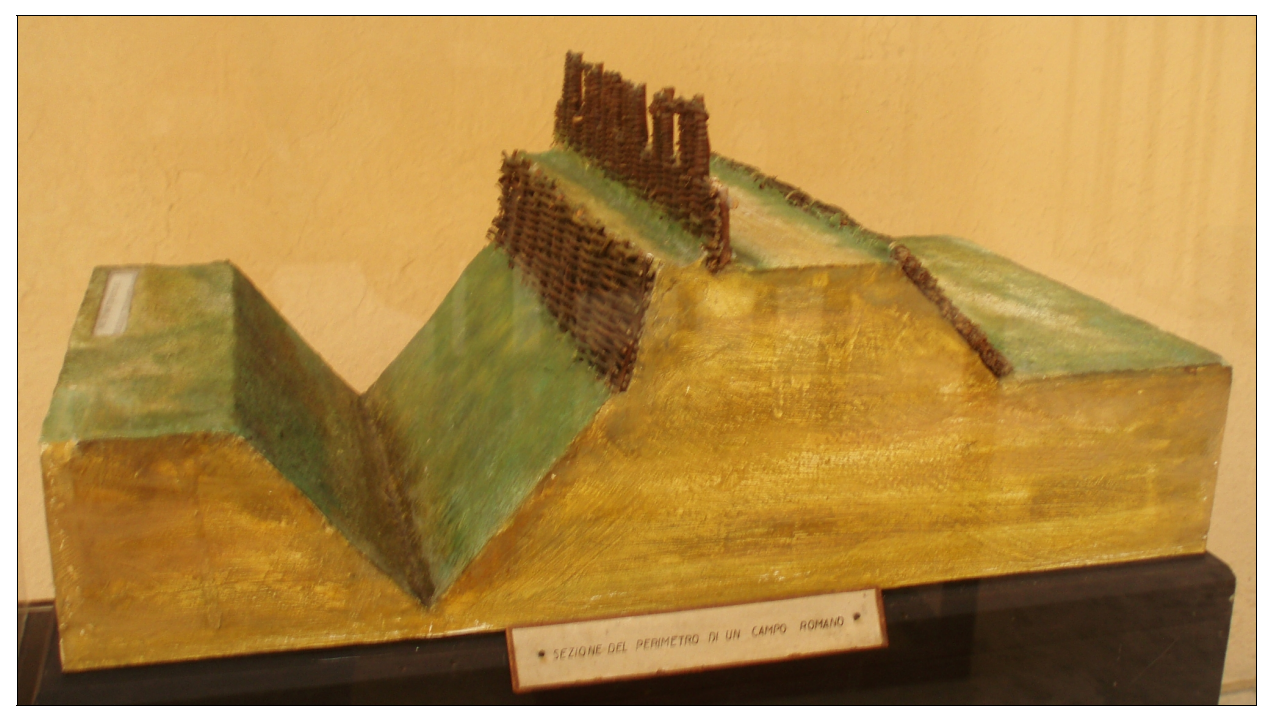

Fig. 3. Reconstrucción de la sección del perímetro de un campamento romano (Museo Della Civiltà Romana, Roma). 